\title{
FORMATION OF THE RECEPTIVE FIELDS OF LEECH MECHANOSENSORY NEURONS DURING EMBRYONIC DEVELOPMENT ${ }^{1}$
}

\author{
ANDREW P. KRAMER ${ }^{*}, 2$ AND JOHN Y. KUWADA

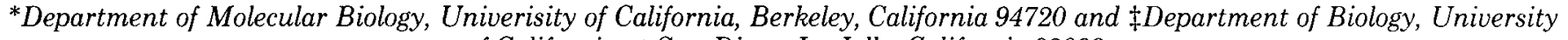 \\ of California at San Diego, La Jolla, California 92093
}

Received February 22, 1983; Revised May 26, 1983; Accepted June 13, 1983

\begin{abstract}
We have charted the embryonic development of the epidermal receptive fields of the $P_{V}$ and $P_{D}$ mechanosensory neurons present in each segmental ganglion of the ventral nerve cord of the glossiphoniid leech Haementeria ghilianii. The receptive field of either of these neurons is established by several peripheral axons, each of which grows into its own skin territory, so that the receptive field is subdivided into a quiltwork of contiguous, mutually exclusive subfields of various sizes. The largest subfield develops first from the primary peripheral axon of the $P_{D}$ or $P_{V}$ neuron. The $P_{D}$ and $\mathrm{P}_{\mathrm{V}}$ primary axons grow directly to their respective territories and begin to innervate them at approximately the same time (see also Kuwada, J. Y., and A. P. Kramer (1983) J. Neurosci. 3: 20982111). The smaller secondary and minor subfields develop later from the secondary and intersegmental peripheral axons, respectively. These axons, too, grow directly to their appropriate skin territories. The arborizations of the peripheral axons expand until the adult receptive field pattern is established late in embryogenesis; they do not appear to initially overgrow and later trim down to the normal boundaries of the adult receptive field. The receptive field of the $P_{V}$ neuron develops from a stereotyped skeletal branching pattern of the peripheral axons that is elaborated in a regular way to form a grid-like pattern that matches the arrangement of muscle fibers in the body wall. Thus, this branching pattern may be the result of axon growth along prespecified pathways, perhaps delineated by the muscles. Throughout embryonic development, as in the adult leech, axon branches of neighboring homologous P neurons overlap considerably, but separate axon branches of the same neuron are virtually non-overlapping. These observations suggest that developing branches of a neuron are excluded from territory occupied by other branches of the same cell, in contrast to branches belonging to different neurons which can occupy the same territory.
\end{abstract}

The mechanosensory neurons in the ventral nerve cord of the glossiphoniid leech Haementeria ghilianii are particularly suitable for examining how neuronal processes find a specific set of target cells during development. Each mechanosensory neuron projects axons from the

\footnotetext{
${ }^{1}$ This research was supported by postdoctoral fellowships from the National Science Foundation (SPI 79-14849 to A. P. K. and SPI 8009177 to J. Y. K.) and the National Institutes of Health (NS 06456 to A. P. K. and NS 06551 to J. Y. K.) and by research grants from the National Science Foundation (Grants BNS 79-23459 and BNS 7912400 ) and the National Institutes of Health (Grant NS 12818). We thank W. B. Kristan, G. S. Stent, C. S. Goodman, and W. $\Lambda$. Harris for helpful discussions and for comments on the manuscript. We are grateful to Nicholas Spitzer for generously sharing his time and experience to help us learn how to do intracellular work on the embryos. We are indebted also to Paul Taghert for supplying us with serum antibody against Lucifer Yellow.

${ }^{2}$ To whom correspondence should be addressed.
}

CNS into a particular territory of skin, where endings of the axons form specialized mechanoreceptors (Blackshaw, 1981a, b). The territory of skin innervated by these receptors is the neuron's receptive field. In each segmental ganglion of the Haementeria CNS, there are two bilateral pairs of mechanosensory P (for "pressure") neurons that respond to moderate deformation of the skin, designated as $\mathrm{P}_{\mathrm{V}}$ and $\mathrm{P}_{\mathrm{D}}$ (Kramer and Goldman, 1981). They are homologous to the $P_{V}$ and $P_{D}$ neurons first identified by Nicholls and Baylor (1968) in the hirudinid leech Hirudo medicinalis. These neurons have distinct peripheral axon branching patterns and receptive fields in the ipsilateral segmental skin; the field of $P_{V}$ occupies the ventral skin and that of $P_{D}$ occupies the dorsal as well as much of the ventral skin (Kramer and Goldman, 1981). The embryonic development of these mechanosensory neurons can be followed from the time of the initial outgrowth of their axons. Their initial 
growth is directed along specific pathways that lead to their appropriate receptive field territories (Kuwada and Kramer, 1983).

In the work presented here, the embryonic growth pattern of the peripheral axons of the $P_{V}$ and $P_{D}$ mechanosensory neurons has been followed anatomically to determine how these neurons construct their respective receptive fields. Do they initially innervate only the appropriate territory of skin or do they also innervate inappropriate skin territory from which their axons later withdraw? Another question we addressed arises from the following situation. In the adult leech, the receptive field of each mechanosensory neuron is divided into subfields, each of which is innervated by a different peripheral axon. These subfields occupy contiguous but non-overlapping areas of skin. However, these same subfields overlap extensively with the receptive fields of neighboring homologous mechanosensory neurons (Nicholls and Baylor, 1968; Yau, 1976; Kramer and Goldman, 1981). Is it possible, then, that receptive subfields are non-overlapping in the adult because, during development, the different peripheral axons growing from the same neuron avoid each other or compete for a place on their common target? If this were the case, and it appears to be, axons belonging to the same neuron would have to be distinguishable from axons belonging to the homologous neurons with which they can share the same area of skin.

\section{Materials and Methods}

The materials and methods used in the experiments of this paper are the same as those described in a previous paper (Kuwada and Kramer, 1983). That paper also presents a general description of the early development of the $H$. ghilianii nervous system and skin territories and an explanation of the system of developmental staging used here. Briefly, stages are indicated by a stage number followed by a fraction in parentheses, which is the fraction of the total duration of the stage that has been completed; the denominator is the stage duration in days.

\section{Results}

\section{Innervation of differential skin territories by $P_{V}$ and $P_{D}$ neurons during development}

How does each of the several peripheral axons extended by the $P_{V}$ and $P_{D}$ neurons come to occupy its appropriate skin territory? To address this question we followed the growth of these neurons' axons in the periphery, but before describing the pattern of that growth, it is necessary to review the adult structure of these neurons' receptive fields, which forms the developmental endpoint of our study. The skin of the leech can be divided into 32 segments, each of which is innervated principally by one of the 32 ganglia of the ventral nerve cord (Mann, 1962; Muller et al., 1981). In every midbody segment, the skin of $H$. ghilianii is subdivided into five annuli on the ventral aspect and three annuli on the dorsal aspect, of which the middle one is referred to as the central annulus. The receptive fields of the $\mathrm{P}_{\mathrm{V}}$ and $P_{D}$ neurons are centered in the ipsilateral skin of their own segment and extend into the skin of the adjacent anterior and posterior segments. Also, the field of the $P_{V}$ neuron extends across the ventral midline and overlaps with the field of the contralateral $P_{v}$, and the field of $P_{D}$ crosses the dorsal midline and overlaps with that of the contralateral $\mathrm{P}_{\mathrm{D}}$. The receptive field of each neuron is divided into non-overlapping subfields: a major subfield, which is established by axons that project into the segmental skin from the segmental ganglion in which the cell body of the neuron is located, and anterior and posterior minor subfields, which are established by intersegmental axons that project from the adjacent anterior and posterior ganglia into the skin of the adjacent segments (Fig. 1). The major subfield is further divided into non-overlapping primary and secondary subfields (A. P. Kramer and J. R. Goldman, manuscript in preparation), which are established, respectively, hy the first (primary) peripheral axon to grow out of the ganglion during development and the subsequent (secondary) axons to grow out (Kuwada and Kramer, 1983). The primary subfield of $\mathrm{P}_{\mathrm{V}}$ lies largely in the ipsilateral ventral half of the skin segment, and that of $\mathrm{P}_{\mathrm{D}}$ lies in the ipsilateral dorsal half of the skin segment. Both $P_{V}$ and $P_{D}$ also have smaller secondary subfields in the ventral skin (Fig. 1).

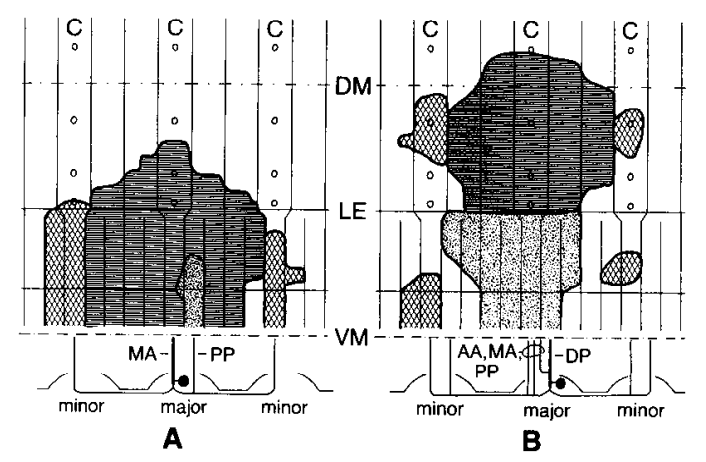

Figure 1. Configuration of averaged receptive field territories of the $\mathrm{P}$ mechanosensory neurons in adult Haementeria (from A. P. Kramer and J. R. Goldman, manuscript in preparation). Receptive fields are mapped on a schematic representation of three segments of skin on one side of the leech from ventral $(V M)$ to dorsal $(D M)$ midlines. Although mapped on separate skin representations, the fields of $P_{v}$ and $P_{D}$ actually lie in the same skin segments. $L E$ is the lateral edge of the body. Leech skin is divided into a series of rings around the body, the annuli. Each body segment is divided into three annuli in dorsal skin and five annuli in ventral skin; the central annulus $(C)$ is the middle annulus of the segment. The complete receptive field of each $P$ neuron is outlined in bold lines, except for portions of the field that cross the ventral midline, which have been left out. Shaded and stippled regions together constitute the major subfield, that is founded by axons originating in the segmental ganglion; cross-hatched regions are the minor subfields that are founded by axons exiting adjacent ganglia. The shaded region of the major subfield is territory innervated by the primary axon of the neuron (schematically shown as a thick line) and the stippled region is territory innervated by the secondary axons of the neurons (thin lines). Anterior is to the left in this and other figures. $A$, Field of the $\mathrm{P}_{\mathrm{v}}$ neuron. Its primary axon courses in the MA nerve and its secondary axon courses in the PP nerve. $B$, Field of the $\mathrm{P}_{\mathrm{D}}$ neuron. Its primary axon courses in the DP nerve and has secondary axons in the MA, PP, and AA nerves. 
First we consider how the $P_{V}$ and $P_{D}$ neurons form their primary subfields during embryonic development. This was determined by injecting Lucifer Yellow dye into their cell bodies at various stages. These subfields are established by the primary peripheral axons, which are first to grow out of the ganglion. The primary axons of the two neurons have different peripheral targets: the ventral germinal plate for the $\mathrm{P}_{\mathrm{V}}$ axon and the dorsal germinal plate for the $P_{D}$ axon. (The ventral or the dorsal germinal plate is that sheet of embryonic tissue which eventually gives rise to the ventral or dorsal body wall and skin, respectively (Kuwada and Kramer, 1983).) At the very outset of peripheral outgrowth, both $\mathrm{P}_{\mathrm{V}}$ and $\mathrm{P}_{\mathrm{D}}$ project neurites into the same region of the ventral germinal plate that lies next to the ganglion (Kuwada and Kramer, 1983). However, by the beginning of stage 10 (2 to 3 days after the start of peripheral process outgrowth), $\mathrm{P}_{\mathrm{D}}$ and $\mathrm{P}_{\mathrm{V}}$ primary axons have grown into different regions of the germinal plate (Fig. $2 A$ ). Without forming branches, the primary axon of the $P_{D}$ neuron takes one circumferential route, which later becomes the dorsal posterior $(D P)$ nerve, directly to the dorsal germinal plate; there it branches extensively. Meanwhile, the primary axon of the $P_{v}$ neurons grows more slowly along another circumferential route, which later becomes

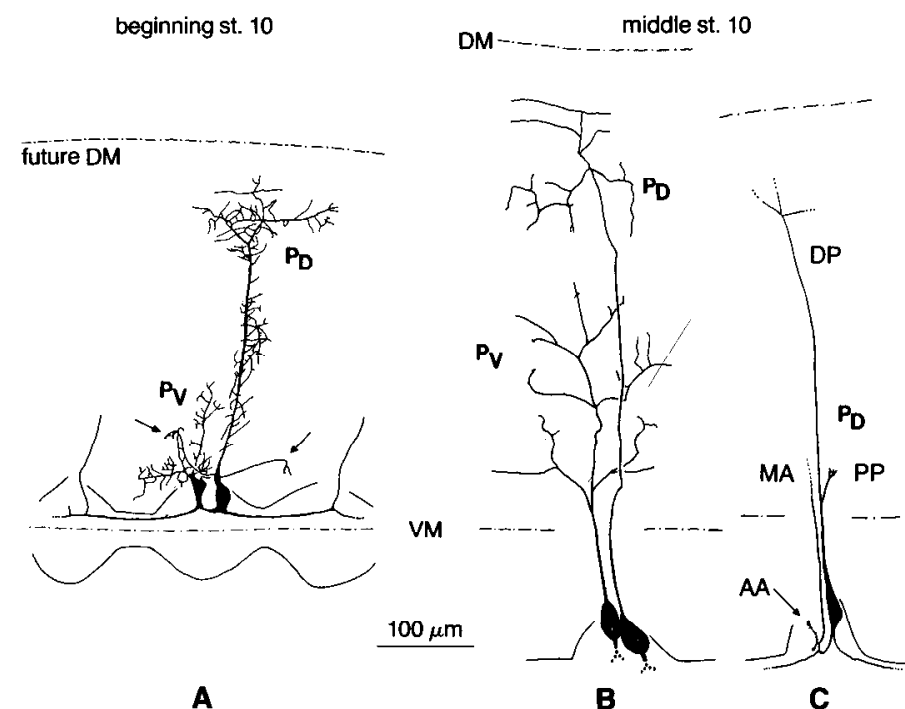

Figure 2. Tracings made from photographs of whole mounted preparations of $P_{V}$ and $P_{D}$ neurons in the same ganglion filled with Lucifer Yellow dye to show comparative growth of their peripheral axons at various developmental stages. $A$, The $\mathrm{P}_{\mathrm{v}}$ and $P_{D}$ neurons at stage $10(0 / 5) . P_{v}$ arborizes in the ventral and $\mathrm{P}_{\mathrm{D}}$ in the dorsal germinal plate. Arrows point to a pair of neurites left in the ventral germinal plate by the $P_{D}$ neuron. The fine branches on the $P_{D}$ primary axon between ventral and dorsal fields are lateral filopodia. $B$, The $\mathrm{P}_{\mathrm{V}}$ and $\mathrm{P}_{\mathrm{D}}$ neurons 2 days later at stage $10(2 / 5)$. At this stage all ventral neurites of the $\mathrm{P}_{\mathrm{D}}$ neuron have disappeared. $C$, Another $\mathrm{P}_{\mathrm{D}}$ neuron also at stage $10(2 / 5)$. Secondary axons $(M A$ and $P P)$ have grown out of the ganglion, or are beginning to grow out $(A A)$, into the ventral germinal plate where they will form receptive subfields. At this stage, secondary axons have minimal arborizations in the germinal plate. These secondary axons overlap with the axon branches of the $\mathrm{P}_{\mathrm{v}}$ neuron in the same ganglion (not drawn). In this and other tracings, dotted lines indicate a process that continues but has not been drawn. the medial anterior $(M A)$ nerve. Unlike the $\mathrm{P}_{\mathrm{D}}$ primary axon, the $\mathrm{P}_{\mathrm{V}}$ primary axon branches extensively in the ventral germinal plate. At this stage, the $P_{D}$ neuron can still have a few of the initial neurites in the ventral germinal plate (Fig. 2A), remnants of its passage through that region (Kuwada and Kramer, 1983). These remnant neurites later disappear, so that by middle stage 10 , the primary $P_{V}$ and $P_{D}$ axons occupy completely separate and appropriate territories of the germinal plate (Fig. $2 B$ ). At later stages, the primary subfield of the $\mathrm{P}_{\mathrm{V}}$ neuron expands into the dorsal germinal plate and by stage 11 begins to overlap there with the primary subfield of the $P_{D}$ neuron. Thus the primary axons of these two neurons grow initially to different, non-overlapping territories, although they can and do overlap extensively at later stages.

Next we consider how the secondary subfields form. The secondary peripheral axons, which establish these subfields, grow out at a later stage than do primary axons. These secondary axons also grow directly to their appropriate territories, which for both $P_{V}$ and $P_{D}$ neurons lie in the ventral germinal plate. For example, at about the time that the remnant neurites of the primary $P_{D}$ axon are disappearing, the $P_{\mathcal{D}}$ neuron begins to extend a secondary axon into the periphery from its central processes in the ganglion (Fig. 2C). This secondary axon, which grows directly into the MA nerve during early stage 10 , branches in the ventral germinal plate and eventually establishes most of the secondary $P_{D}$ subfield in the ventral skin. In some cases, the $P_{D}$ neuron extends two more secondary axons, which also grow directly into the ventral germinal plate during stage 10 , one in the anterior anterior $(A A)$ nerve and the other in the posterior posterior $(P P)$ nerve (Fig. $2 C$ ).

\section{Development of the receptive field of the $P_{V}$ neuron}

To describe the details of the formation of a mechanosensory neuron receptive field, we closely followed the anatomical development of the peripheral axons of the $P_{V}$ neuron. A series of $P_{v}$ neurons was filled with Lucifer Yellow dye at successive stages of development, from the time of initial axon outgrowth late in stage 9 through mid-stage 11 , by which time the receptive field has achieved its adult configuration. Twenty to 50 neurons were examined at each daily stage through stage $11(5 /$ 20), 4 neurons were examined at stage $11(6 / 20)$, and 6 neurons were examined at stage $11(9 / 20)$.

Formation of the major receptive subfield. Not only does the $\mathrm{P}_{\mathrm{V}}$ neuron grow directly to its peripheral target territory, but it arborizes in that territory in a very regular way, as if its peripheral axons are growing along predetermined pathways. The axonal arborization is sufficiently stereotyped in its development that the main branches can be individually named, and even the subsidiary branches grow in the same general pattern from cell to cell. To describe these regularities of axon outgrowth, it is useful to resort to the special nomenclature introduced in the following paragraphs, where the generic names given to types of branches and individual designations given to identified branches are italicized when first mentioned.

The peripheral outgrowth of $P_{V}$ begins between stages 
$9(2 / 4)$ and $9(3 / 4)$ with the extension of a single neurite from the lateral pole of the cell body (Fig. $3 A$ ). This is the primary axon that will give rise to most of the major subfield. Its central branch grows circumferentially, perpendicular to the long axis of the embryo, along that area of the germinal plate from which will arise the central annulus of the segmental skin (see Fig. 1). As this central axon branch elongates, axon branches directed both anteriorly and posteriorly emerge from it perpendicularly at three characteristic circumferential positions. These first-order longitudinal branches are designated $B 1, B 2$ and $B 3$, with the addition of the letters $a$ or $p$ indicating anterior- or posterior-directed branches, respectively (in accord with the designation of peripheral nerve branches by Ort et al. (1974) and Kretz et al. (1976)). The B1 branches are closest to the ventral midline and the first to emerge, at about stage $9(3 / 4)$ (Fig. $3 A)$. The B2 branches emerge next at stage $10(0 / 5)$, about halfway between the ventral midline and the future lateral edge of the body wall (Fig. $3 B$ ). The B3 branches are the last to emerge, near the future lateral edge (Fig. $3, B$ and $C$ ). Any branches that emerge subsequently from the central axon branch at circumferential positions distal to the B3 branches, although also "first order" from a topological point of view, are considered here to be part of the terminal arborization pattern of the central branch (Fig. $3, C$ and $D$ ). Moreover, some additional, very short longitudinal branches sometimes emerge from the central branch proximal to the B3 branches, particularly between the B1 and B2 branches. Such additional longitudinal branches are most frequently observed during stage 10 (Fig. $3, B$ to $D$ ) and less often during stage 11 (Fig. 3, $E$ and $F$ ), suggesting that some of them disappear during stage 11. Furthermore, in less than $1 \%$ of the cases examined (an example is in Fig. $7 E$ ) did these additional longitudinal branches eventually form the large arborization typical of the three regular first-order longitudinal branches.

It appears, therefore, that the central branch of the primary $\mathrm{P}_{\mathrm{V}}$ axon normally begins its peripheral arborization with formation of the $\mathrm{B} 1, \mathrm{~B} 2$, and $\mathrm{B} 3$ branches. Furthermore, in a given specimen, the B1, B2, and B3 branches of homologous $P_{v}$ neurons in adjacent segments usually emerge from the central branch at equivalent circumferential positions and grow along the same longitudinal perimeter. Accordingly, some homologous firstorder branches growing toward each other from adjacent segments may eventually collide. For example, as seen in Figure $7 A$, the $\mathrm{B} 1 \mathrm{a}$ and $\mathrm{B} 2 \mathrm{a}$ branches of $\mathrm{P}_{\mathrm{v}}$ of the posterior segment (on the right) exactly meet and overlap with the $\mathrm{B} 1 \mathrm{p}$ and $\mathrm{B} 2 \mathrm{p}$ branches of $\mathrm{P}_{\mathrm{V}}$ of the anterior segment (on the left). The B3 branches, however, usually do not collide, because most often they grow longitudinally only for a short distance and then make a lateral turn (see following subsection).

As the first-order branches, B1, B2, and B3, grow longitudinally, axon branches emerge from them perpendicularly at characteristic longitudinal positions. These second-order annular branches grow circumferentially along the central portions of the future skin annuli, both medially and laterally from the B1 branches, but grow predominantly laterally from the $\mathrm{B} 2$ and $\mathrm{B} 3$ branches
(Fig. $3, C$ to $E$ ). Whereas growth of the first-order longitudinal branches extends the major field toward the central annuli of adjacent segments, growth of the annular branches increases the density of innervation of the field and spreads it circumferentially. Annular branches cross the future lateral edge and enter the dorsal germinal plate by mid-stage 10 (Fig. $3 D$ ), and they cross the ventral midline by early stage 11 (Fig. $3 E$ ).

The density of innervation of the field is increased further by the emergence of yet a higher order of branches. Between mid-stage 10 and early stage 11 , thirdorder longitudinal branches emerge perpendicularly from the second-order annular branches, closely and evenly spaced (Fig. 3, $D$ and $E$ ).

This consistently rectilinear pattern of axon branching and growth probably reflects a corresponding arrangement of some patterning agent or agents in the germinal plate. One of these agents may be the grid of embryonic muscle fibers whose initial development precedes the outgrowth of the peripheral $\mathrm{P}_{\mathrm{V}}$ axon (Kramer and Stuart, 1982). The central branch of that axon, as well as its first-, second-, and third-order branches, all grow into the germinal plate between an inner layer of longitudinal muscle fibers and an outer layer of circular muscle fibers. First-order and third-order longitudinal branches are aligned with longitudinal muscle fibers, and the central branch and second-order annular branches are aligned with circular muscle fibers (Fig. 4). Thus the branches form a grid-like pattern (e.g., Fig. 7A) that matches the grid formed by orthogonal longitudinal and circular muscle fibers in the germinal plate.

Formation of sensory endings. The final phase of receptive field formation is the development of sensory endings. These endings are formed by fourth-order circular branches, which begin to emerge from the tips of third-order longitudinal branches early in stage 11 (Fig. $3 F$ ). These circular branches are directed toward the surface of the germinal plate and appear to grow between the circular muscle layer and the epidermis, forming parallel rows in alignment with the circular muscle fibers (Fig. $3 F$ ). Each row consists of a series of circular branches which have emerged from different third-order longitudinal branches and which grow aligned with the same circular muscle fiber (Fig. 9B). Thus the correspondence of axon branching pattern and arrangement of muscle fibers is carried even to the level of the fourthorder branches of the central axon branch. After stage $11(2 / 20)$, the circular branches proliferate fine, branched endings into the overlying epidermis. These endings eventually spread into the space between the parallel rows of circular branches, so that the entire epidermis overlying the $\mathrm{P}_{\mathrm{V}}$ axon and its branches becomes densely innervated. Axon endings in the skin are irregularly shaped and distributed (Fig. $5 A)$. They are thin $(0.2$ to $0.4 \mu \mathrm{m}$ ), finger-like processes with occasional swellings at branch points and along their length. Some endings are completely bare along their length (Fig. $5 B$ ), whereas others carry very fine processes (Fig. $5 C$ ). In several respects, they resemble the skin endings of the mechanosensory $\mathrm{T}$ neurons in the adult skin of $H$. medicinalis (Blackshaw, 1981b). Electrophysiological studies not presented here have shown that, by this stage, the axon 

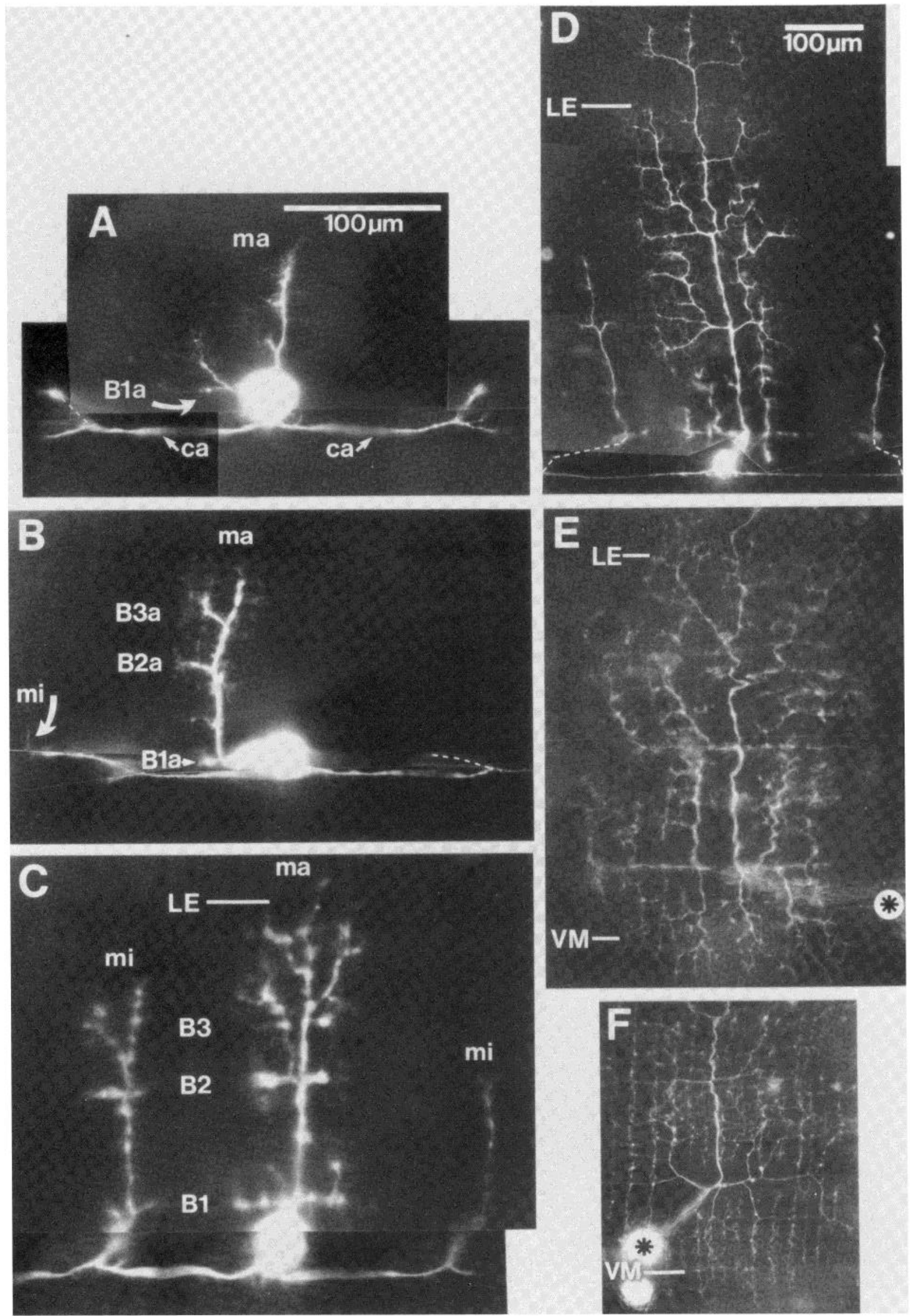


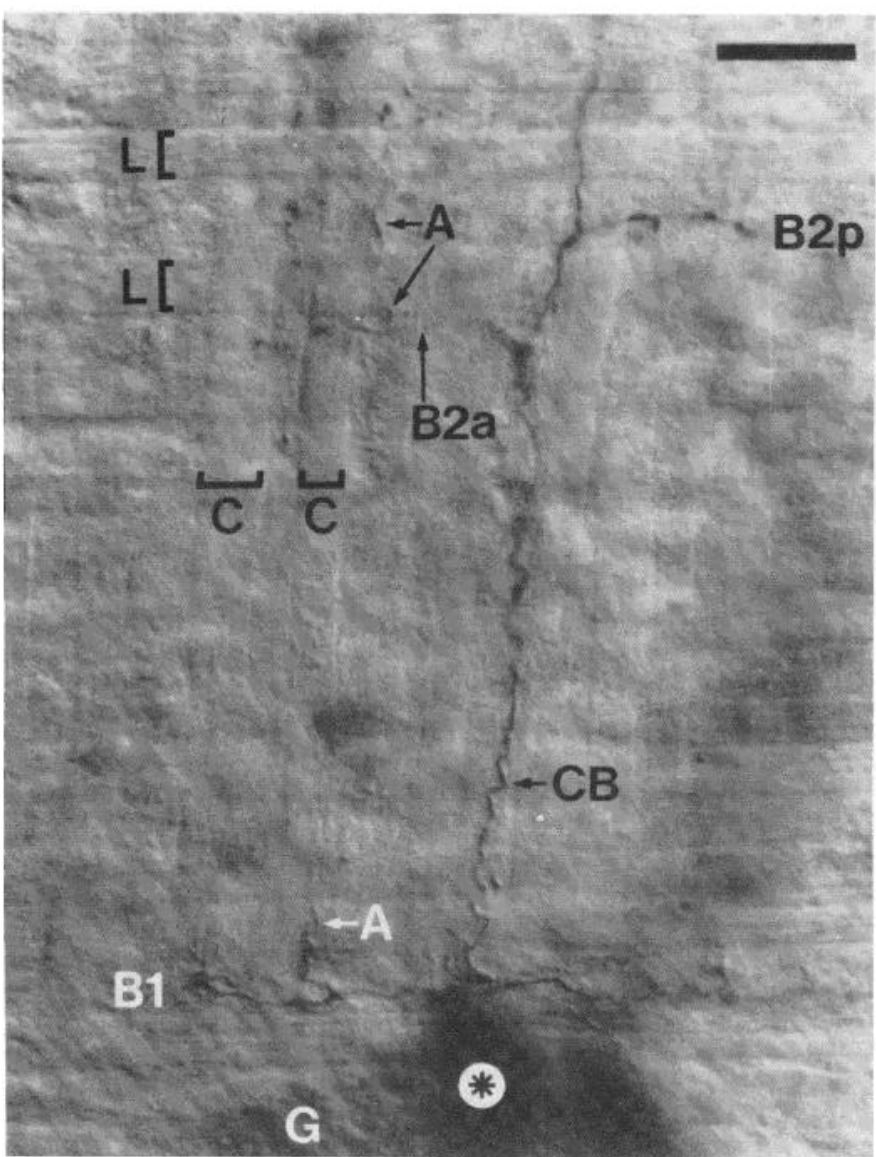

Figure 4. Alignment of peripheral axon branches of a $\mathrm{P}_{\mathrm{V}}$ neuron with muscle fibers in the ventral germinal plate of a stage $10(2 / 5)$ embryo. Photomicrograph shows the $\mathrm{P}_{\mathrm{v}}$ neuron, stained with horseradish peroxidase using a Lucifer Yellow antibody technique (Taghert et al., 1982), and the unstained muscle fibers viewed in whole mount under Nomarski optics. $L$ indicates a longitudinal muscle fiber and $C$ a circular muscle fiber. There are spaces between adjacent muscle fibers. Oblique muscles are not present at this stage. $G$ is the ganglion and the endings are capable of transducing mechanical stimulation of the skin into action potentials that are conducted to the $\mathrm{P}_{\mathrm{V}}$ cell body in the segmental ganglion.

Formation of the minor subfields. The minor subfields, which the $\mathrm{P}_{\mathrm{v}}$ neuron establishes in the skin of the adjacent anterior and posterior segments, arise from anteriorly and posteriorly directed branches of the central axon projected from the cell body into the neuropilar region of the ganglion at stage $9(1 / 4)$ (Kuwada and Kramer, 1983). These branches enter the connective nerve and, after reaching the next ganglion, turn and leave the CNS to enter the germinal plate of the adjacent segment (Fig. 3, $B$ to $D$ ). The pattern of minor field axon outgrowth and branching is also highly stereotyped and resembles that of major field axon outgrowth. The firstorder longitudinal branches projected from the central axon branch of the minor field grow along the same longitudinal perimeter as do those of the major field of the same $\mathrm{P}_{\mathrm{V}}$ neuron. Moreover, the minor field axon emerges from its ganglion only after the serially homologous $\mathrm{P}_{\mathrm{v}}$ neuron in the same ganglion has already begun to establish its own major field. By filling serially adjacent $\mathrm{P}_{\mathrm{V}}$ neurons with Lucifer Yellow dye, it is evident that the central branch and the first-order longitudinal branches of the minor field axon usually follow the paths previously taken by the corresponding branches of the serially homologous major field axon. One difference between minor field and major field axon outgrowth is that in the minor field, the branches usually grow much more slowly and are shorter (Fig. 3, $C$ and $D$ ). However, minor field axons that exit the clitellar or sex (5th and 6 th abdominal) ganglia are noticeably thicker than those in other ganglia, and they establish much larger fields (Figs. $3 C$ and $7 B$ ).

asterisk is on the $\mathrm{P}_{\mathrm{v}}$ cell body. Branches of peripheral axon are as follows: $C B$ is the central branch, $\mathrm{B} 1$ and $\mathrm{B} 2$ are first-order longitudinal branches, and $A$ is the second-order annular branch. Calibration, $20 \mu \mathrm{m}$.

Figure 3. Successive stages of development of the peripheral axons of the $\mathrm{P}_{\mathrm{v}}$ neuron filled with Lucifer Yellow and photographed in whole mounts. All neurons are located in the 10th or 11th midbody ganglia, except the neuron in $C$ which is in the 7 th ganglion. Note that in these and other pictures of this kind, there is almost always some distortion of the axon branching patterns because the dissected preparation often stretches asymmetrically as it is pinned out. Ganglia, and thus cell bodies, are often displaced longitudinally from the position where the primary axon enters the germinal plate (as in $E$ and $F$ ). Cell bodies are out of focus; hence their size is exaggerated by spread of the fluorescent emission. Dashed lines are drawn in to show out-offocus processes. $A$ to $C$ are shown at the same magnification and $D$ to $F$ are shown at half this magnification. $A$, Stage $9(3 / 4)$. Primary axon that will establish the major $(m a)$ field has entered the germinal plate. A longitudinal, first-order B1a axon branch is just sprouting from the central branch of the primary axon. Central axons ( $c a$ ) extend into adjacent ganglia but do not yet enter the periphery. The finest processes seen in this photograph and in those of $B$ to $D$ are filopodia. $B$, Stage $10(0 / 5)$. B1a, $\mathrm{B} 2 \mathrm{a}$, and $\mathrm{B} 3 \mathrm{a}$ branches are present, as is a short longitudinal branch between $\mathrm{B} 1$ and $\mathrm{B} 2$. A minor ( $m i)$ field axon has just grown out of the next anterior ganglion (at arrow). C, Stage 10(1/5). All three first-order longitudinal branches are present and some second-order annular branches have appeared. An annular branch that emerges from the B2a branch has grown into the normal territory of the B3a branch, which is missing. The anterior minor field axons innervate the skin of the 6th (clitellar) segment; their growth is much more advanced at this stage than that of minor field axons in midbody segments. $D$, Stage $10(3 / 5)$. Secondorder annular branches are well developed and third-order longitudinal branches have begun to emerge from them. The major field axons occupy nearly a full segment width. They have grown across the lateral edge $(L E)$. First-order longitudinal branches have just emerged from minor field axons. $E$, Stage $11(0 / 20)$. View of the major field axons only. First-order longitudinal branches are longer and new second-order annular branches have grown from the new extensions; there are numerous third-order longitudinal branches. The axons have crossed the ventral midline $(V M)$. The cell body is out of view to the right of the asterisk. $F$, Stage $11(2 / 20)$. View of a portion of the major field axons only. Parallel rows of fourth-order circular branches are well developed. An additional cell body in the ganglion had been filled with dye and appears beneath that of the $\mathrm{P}_{\mathrm{v}}$ neuron (with asterisk); its processes are not visible in the photograph. 

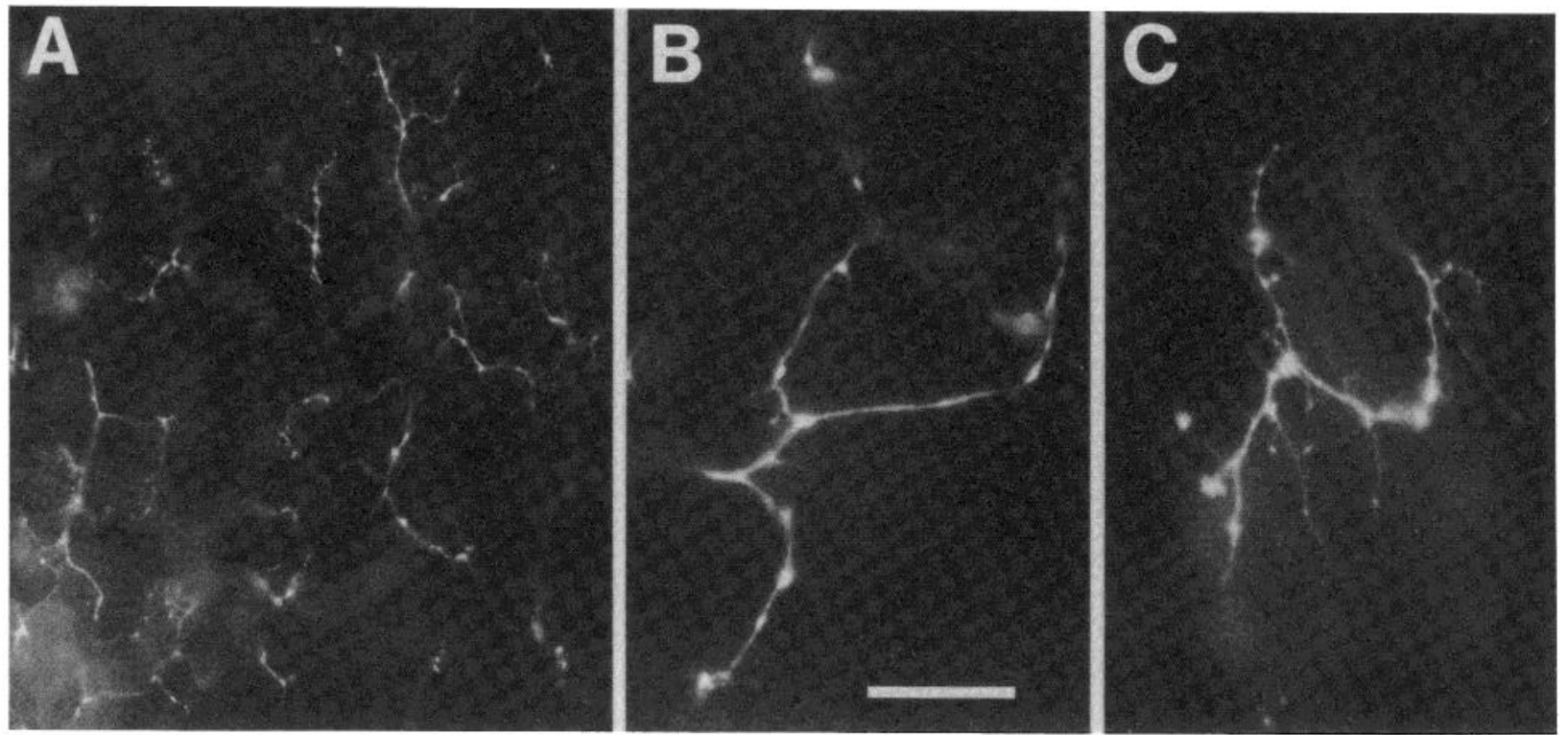

Figure 5. Photographs of skin endings of a $\mathrm{P}_{\mathrm{v}}$ neuron filled with Lucifer Yellow in a fixed whole mounted preparation. A, Low magnification view in embryo at stage 11(5/20). Endings are near but beneath the surface of the epidermis. $B$, High magnification view in an embryo at stage $11(6 / 20)$. $C$, Different ending in same preparation as in $B$. The thinnest processes may be filopodia. Calibration: $A, 40 \mu \mathrm{m} ; B$ and $C, 10 \mu \mathrm{m}$.

Formation of subfield boundaries. A striking feature of the subfields of individual mechanosensory neurons in the adult leech is that they form sharp boundaries, without significant overlap (Nicholls and Baylor, 1968; Yau, 1976; Kramer and Goldman, 1981). In this section, we consider how these sharp subfield boundaries are established during development, focusing attention first on the boundary between the major and minor subfields. As described above, the B1 and B2 first-order longitudinal branches of both the major and minor field axons projected by one $\mathrm{P}_{\mathrm{v}}$ neuron grow toward each other along the same longitudinal perimeter and eventually meet. In midbody segments of the embryo, this meeting of major and minor field axons occurs within 1 or 2 days after the start of stage 11 . Their branches come very close, and may even touch in a few cases, but they never grow across each other on the same substrate. This mutual avoidance is to be contrasted with the extensive contact and overlap that follows the meeting of axon branches of two serially or contralaterally homologous $\mathrm{P}_{\mathrm{V}}$ neurons. Formation of the boundary between the major and minor fields of a $P_{V}$ neuron is illustrated in Figure 7. At a stage when the major field axons of serially homologous $\mathrm{P}_{\mathrm{V}}$ neurons in adjacent midbody segments interdigitate extensively (Fig. 7A), the major and anterior minor field axons of an individual $\mathrm{P}_{\mathrm{V}}$ neuron meet but remain separated (Fig. $7 B$ ). They remained separated 2 (Fig. 7, $C$ and $D$ ) and 3 (Fig. $7 E$ ) days later. Even as late as midstage 11 , major and minor field axons of the $P_{V}$ neuron do not overlap, although a few major and minor field branches, particularly the B1 branches, may appear to contact each other. Most of these apparent contacts are, in fact, cases where major and minor axons are in different levels of tissue and have grown a short way over or under each other at a distance of a few micrometers.

It can be inferred, therefore, that the sharp boundary

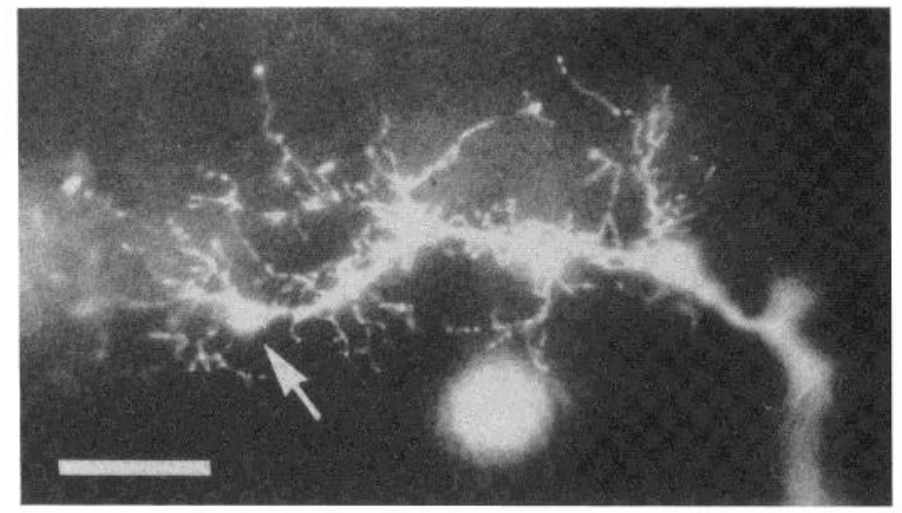

Figure 6. Photograph of growth cone and filopodia of a B1a peripheral axon branch of a $\mathrm{P}_{\mathrm{V}}$ neuron filled with Lucifer Yellow dye at stage $10(1 / 5)$. The arrow indicates the primary growth cone of this branch. The fluorescent circular object beneath the axon is debris. Calibration, $20 \mu \mathrm{m}$.

between the major and minor subfields is established because the major and minor field axons stop growing toward each other when they meet. Although such an encounter usually ends the longitudinal expansion of the major and minor subfields toward each other, the gaps between these subfields, occasionally observed in adult leeches (Fig. 1), indicate that expansion may sometimes end for other reasons prior to their meeting. The growthlimiting effect of the encounter of major and minor field axons was quantified by measuring the elongation of major and minor field B1 branches, which invariably meet head-on during development (Fig. 7, $B$ to $E$ ). On successive days of development, several $\mathrm{P}_{\mathrm{V}}$ neurons were filled with Lucifer Yellow. In each case, the distal ends of the major and minor field B1 branches that were growing toward each other were located and their posi- 
tion relative to the two central annuli between which they grew was recorded. As can be seen in Figure 8, by the 5th day after the beginning of outgrowth, the major field B1 branch, growing from its central annulus of origin (C) toward the central annulus of the next segment $\left(\mathrm{C}^{\prime}\right)$ (Fig. 8, curve through solid points), has met and grown past the major field $\mathrm{B} 1$ branch of a serially homologous $\mathrm{P}_{\mathrm{V}}$ neuron, growing from $\mathrm{C}^{\prime}$ toward $\mathrm{C}$ (Fig. 8, dashed curve) (see also Fig. $7 A$ ). Thereafter, the major field B1 branch approaches but does not grow past the $\mathrm{B} 1$ branch of its minor field, growing from $\mathrm{C}^{\prime}$ toward $\mathrm{C}$ (Fig. 8, curve through open points). The rate of relative growth of the major field B1 branch does not greatly diminish as it approaches the B1 branch of the serially homologous $\mathrm{P}_{\mathrm{V}}$ neuron, but that rate falls to zero as the major and minor field B1 branches approach each other. The minor field $\mathrm{B} 1$ branch is overlapped by the major field $\mathrm{B} 1$ branch of the serially homologous $\mathrm{P}_{\mathrm{v}}$ neuron from the very outset of its growth. Its rate of relative growth falls to zero only as it is approached by its own major field B1 branch. Since the embryo continues to lengthen during subsequent development, the major and minor field B1 branches must also increase their absolute length after meeting, but they do not grow past each other.

There are two other instances of self-encounters by axons of the $\mathrm{P}_{\mathrm{V}}$ neuron; they also result in a limitation of axon growth. First, the annular branches that grow laterally from the $\mathrm{B} 1$ branch eventually encounter the $\mathrm{B} 2$ branch, and the annular branches that grow laterally from the B2 branch eventually encounter the B3 branch (at stage 10(2/5); Fig. 9A). Upon such encounters, the annular branches stop short of the first-order longitudinal branches and never grow across them (see also Figs. $3, D$ and $E$, and $7, B$ and $C$ ). Sometimes it was observed that an annular branch originating from the B2 branch had grown past the normal lateral position of the B3 branch and thus across the B3's longitudinal line of growth. In these cases, either the B3 branch was missing (e.g., B3a is missing in Fig. 3, $C$ and $E$ ) or the B3 branch deviated near the annular branch from its initial line of growth and projected laterally at an oblique angle away from the annular branch (e.g., B3a in Fig. 9A and B3p in Fig. 3D).

The other instance of self-encounter is presented by the fourth-order circular branches that emerge from adjacent third-order longitudinal branches and grow along the same circumferential path. These circular branches are likewise destined for encounter; they grow very close to each other but they do not overlap (Fig. 9B).

It is therefore apparent that whenever axon branches originating from the same $\mathrm{P}_{\mathrm{v}}$ cell body encounter each other on the same substrate during development, they do not cross or overlap and rarely even touch.

Formation of the secondary subfield. In addition to the primary subficld, the major field of the $\mathrm{P}_{\vee}$ neuron occasionally contains a secondary subfield (Fig. $1 A$ ). The primary subfield is established by the primary axon growing out of the ganglion along the path of the future MA nerve, whereas the secondary subfield is established by outgrowth of a secondary axon along the PP nerve, from 2 to 7 days after outgrowth of the primary axon (i.e., during stage 10). In the adult, the primary and secondary subfields are non-overlapping and form sharp boundaries, just as is the case for the major and minor fields of the same neuron (A. P. Kramer and J. R. Goldman, manuscript in preparation). Here too, the nonoverlap appears to be attributable to a growth-limiting effect upon self-encounter of axons originating from the same cell body. Thus, from its initial outgrowth through at least early stage 11 , the branches of the secondary axon come to occupy only that germinal plate territory which is not yet occupied by branches of the primary axon. For example, when a secondary axon is already present at early stage 10 , it occupies that territory which, in its absence, would have been taken by the B1p branch of the primary axon. In this instance, there is no B1p branch, and the branching pattern of the secondary axon actually possesses all general features of the arborization that normally would be derived from the absent B1p branch (Fig. 10A). In other cases, examined later in stage 10 , a $P_{\mathrm{V}}$ neuron can have both a secondary axon and the B1p branch of its primary axon. In this instance, the arborization of the secondary axon occupies a rather small region of the body wall lying between the B1p branch arborization and the ventral midline (Fig. 10B).

Filopodia of outgrowing axons. As will be raised under "Discussion," there may be interactions between outgrowing axons which govern receptive field structure. One way the axons could interact is by contact via filopodia, which protrude from the growing axons throughout stages 9 and 10 of development (Figs. 3, $A$ to $D$, and 9). Filopodia, which extend up to $50 \mu \mathrm{m}$, protrude not only from the growth cones that precede each elongating axon branch but also intermittently along its whole length (Fig. 6). During mid- to late stage 10, each axon branch is surrounded by a halo of filopodia which sometimes nearly fills the space between adjacent branches (Fig. 3D). Examination of whole mounted preparations shows that filopodia on different branches of the same neuron appear to contact each other and adjacent axons. However, the adjacent axons themselves rarely touch directly.

\section{Discussion}

The highly stereotyped structure of the receptive fields of the $\mathrm{P}_{\mathrm{V}}$ and $\mathrm{P}_{\mathrm{D}}$ mechanosensory neurons in the skin of the adult leech (Nicholls and Baylor, 1968; Yau, 1976; Kramer and Goldman, 1981; A. P. Kramer and J. R. Goldman, Manuscript in preparation) could arise by either of two rather different developmental processes. Under one alternative, the embryonic neurons would project into, branch within, and establish sensory endings in the germinal plate more or less at random; the regularity of the location and configuration of the overall receptive field and of its subfields would result from subsequent selective elimination of inappropriately placed branches and endings by trophically or functionally mediated "tuning." Under the other alternative, the regularity of the adult field structure would be the result of a directed axonal growth and patterned branching. It is the latter alternative for which we have found evidence, with the stereotyped growth pattern resulting from two developmental processes working in tandem: (1) initial 

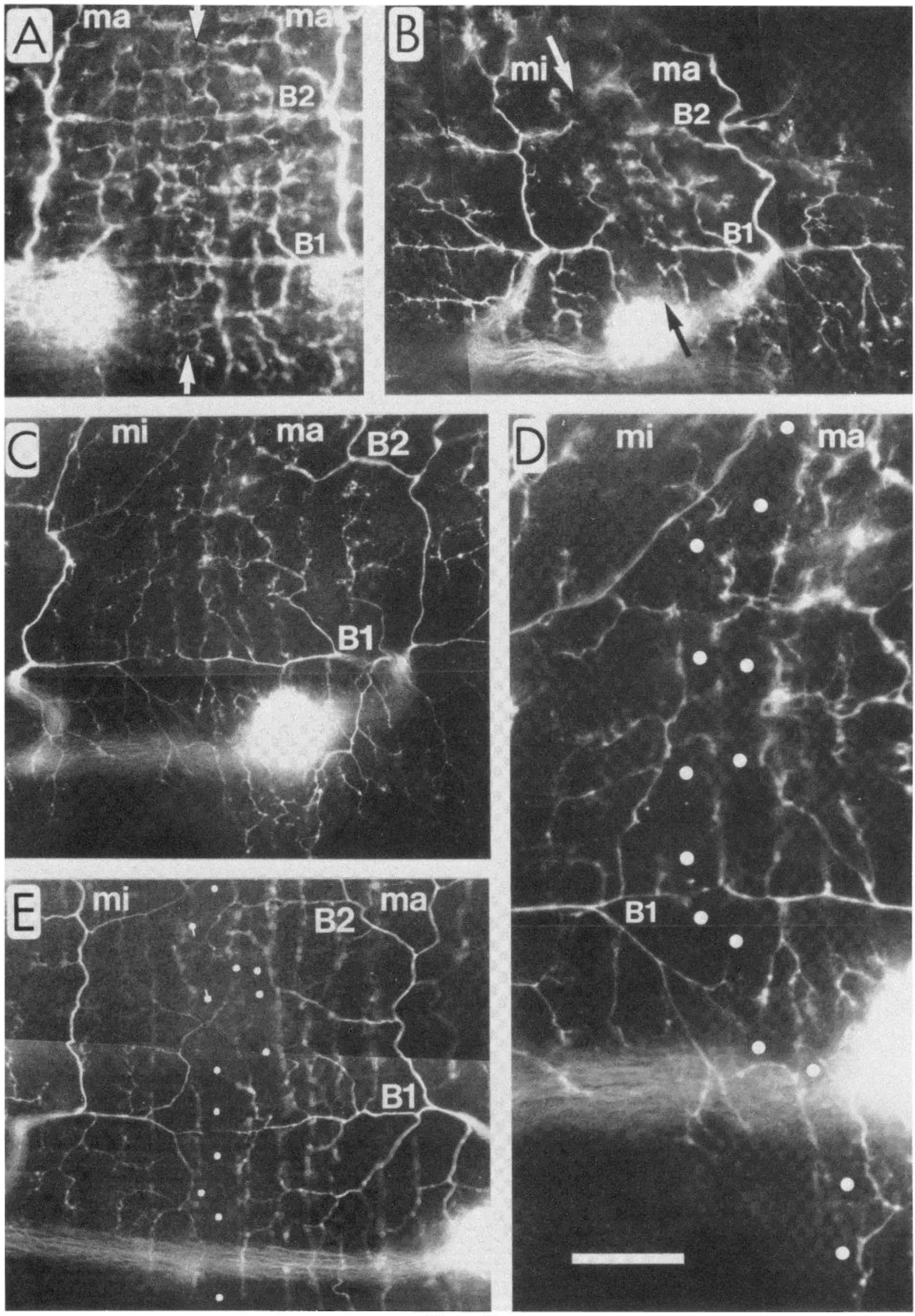


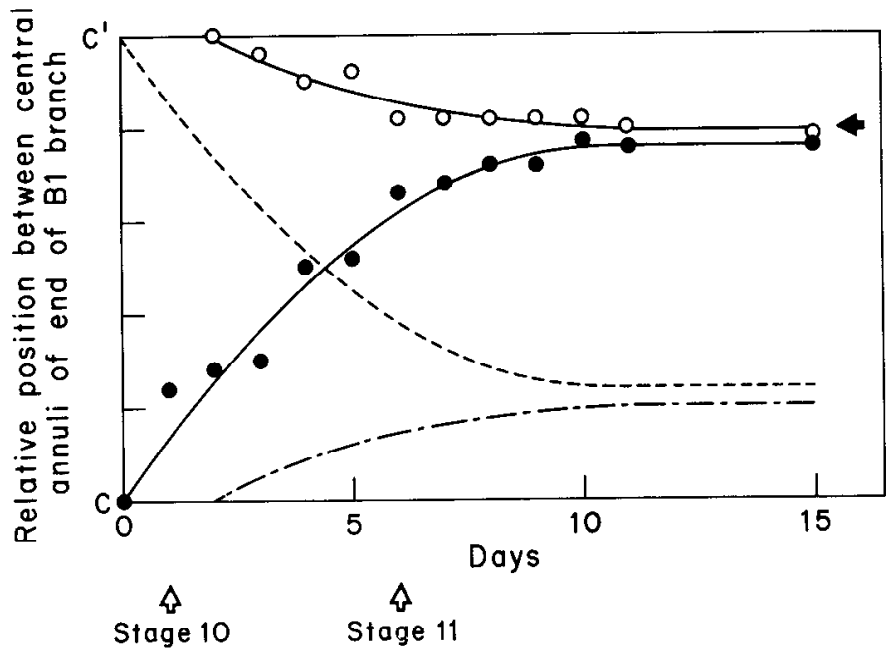

Figure 8. Elongation and approach of the B1 branches of major and minor fields of a $P_{V}$ neuron. On successive days, 2 to $14 \mathrm{P}_{\mathrm{V}}$ neurons were filled with Lucifer Yellow to determine the position of the distal ends of $\mathrm{B} 1$ branches of their major and minor fields. (The origin of this graph lies at the day preceding first outgrowth of the major field B1 branch.) The relative position of the end of the $\mathrm{B} 1$ branch between the middle of the central annulus at which it originated and the middle of the central annulus toward which it was growing was measured for major/minor pairs of $\mathrm{B} 1$ branches. The ordinate shows averages computed for each day. In no specimen had major/minor pairs of $\mathrm{B} 1$ branches grown past each other. The $\mathrm{B} 1$ branches of major and minor field axons originate at positions $\mathrm{C}$ and $\mathrm{C}^{\prime}$, respectively, and the daily positions of their ends are plotted as solid and open circles, respectively. Smooth curves were fitted visually to these points. Inversions of these curves are shown also, to represent the presumptive position of the ends of major (dashed line) and minor (dash-dot line) field $\mathrm{B} 1$ branches of the next serially homologous $\mathrm{P}_{\mathrm{v}}$ neuron that grow between the same $\mathrm{C}$ and $\mathrm{C}^{\prime}$ annuli. The arrow indicates the typical relative position of the boundary between major and minor receptive fields in the skin area innervated by $B 1$ branches in adult leeches.

outgrowth of the several peripheral axons of a neuron preferentially to particular peripheral territories and subsequent growth along particular routes within those territories, and (2) mutual territorial exclusion of these axons. The first process governs the location and general configuration of the receptive field, and the second process governs details of the subfield structure.

Determinants of overall receptive field configuration. Kuffler and Muller (1974), who chanced upon an abnormal adult leceh with supernumerary $P$ neurons in a series of ganglia, observed that the receptive fields of duplicate $P$ neurons were of either a $P_{V}$ or $P_{D}$ type. They concluded that each neuron must have an identity with regard to the peripheral territory it will innervate. In agreement with their conclusion, we find that in normal leeches the $\mathrm{P}_{\mathrm{V}}$ and $\mathrm{P}_{\mathrm{D}}$ neurons exhibit their identity very early in development, by projecting an appropriate set of axons selectively to their appropriate territories (Fig. 2; Kuwada and Kramer, 1983). This is true for all of the peripheral axons of a $\mathrm{P}$ neuron, including the primary axons that grow first, the secondary axons that grow later from the segmental ganglion, and the minor field axons that grow out from adjacent ganglia.

Kuffler and Muller (1974) also observed that the receptive fields of duplicate $P$ neurons of the same type can overlap completely. This makes it unlikely that the overall boundary of the $\mathrm{P}$ neuron receptive field is governed by interneuronal competition. This inference is confirmed by the present developmental studies. First, the territories occupied by axons of serially and contralaterally homologous $\mathrm{P}$ neurons overlap considerably during the middle to late stages of their developmental expansion. Indeed the developing major field of a $\mathrm{P}_{\mathrm{V}}$ neuron hardly slows its expansion as it penetrates the major field of an adjacent serially homologous $\mathrm{P}_{\mathrm{V}}$ neuron, and from the outset of its development, the minor field is completely overlapped by the major field of a serially homologous neuron. Second, the axon fields of the $\mathrm{P}$ neurons expand in their territories only until the adult configuration is attained, early in stage 11 . Thus the receptive field boundaries of the $P$ neurons are established directly, and not by an initial overgrowth followed by elimination of the excess processes, which is a pattern observed in the developing vertebrate nervous system (e.g., Brown et al., 1976; Hubel et al., 1977; Lichtman, 1977; Rakic, 1977; Lichtman and Purves, 1980).

Detailed observations indicate that the process of receptive field development by the $P_{V}$ neuron is indeed direct and highly stereotyped. Receptive field development always begins with a basic axon branching pattern: a central branch that grows out first, along the middle of the future central annulus, from which perpendicular first-order longitudinal branches emerge at three predictable places in the germinal plate (the B1, B2, and B3 branches). Perpendicular second-order annular branches emerge at the middle of adjacent annuli from the firstorder longitudinal branches as they elongate. From the annular branches in turn, third-order longitudinal branches emerge at closely and rather evenly spaced

Figure 7. Formation of the boundary between the major and minor field axons of the $\mathrm{P}_{\mathrm{v}}$ neuron. All panels show neurons filled with Lucifer Yellow photographed in fixed whole mounts. A, Major ( $m a$ ) field axons of $\mathrm{P}_{\mathrm{V}}$ neurons in two adjacent midbody segments at stage $11(0 / 20)$. The intersection of the major fields of the two neurons occurs along a line between the arrows. B1 and B2 longitudinal branches in this and other photographs are labeled. The cell body of the right-hand neuron is out of the picture. $B$ to $E$, Anterior minor ( $m i)$ and major $(m a)$ field axons of $\mathrm{P}_{\mathrm{v}}$ neurons in the 7 th segment. This minor field is atypically large because it lies in the skin of the 6th (clitellar) segment. $B$, Stage $11(0 / 20)$. The boundary between major and minor field axons is along a line between the arrows. $C$ and $D$, Stage $11(2 / 20)$. $D$ is high magnification view of the major/minor field boundary of the neuron shown in $C$. The boundary is along the dotted line. Major and minor $B 1$ branches appear to touch in this photograph, but examination of the whole mount revealed tips of the two branches to be in different focal planes. The same is true of branches between the third and fourth dots from the bottom of the panel. E, Stage 11(3/20). The boundary is along the dotted line. The tapered tips of the major and minor B1 branches apparently do touch. Calibration: $A$ to $C$, and $E, 100 \mu \mathrm{m} ; D, 50$ $\mu \mathrm{m}$. 

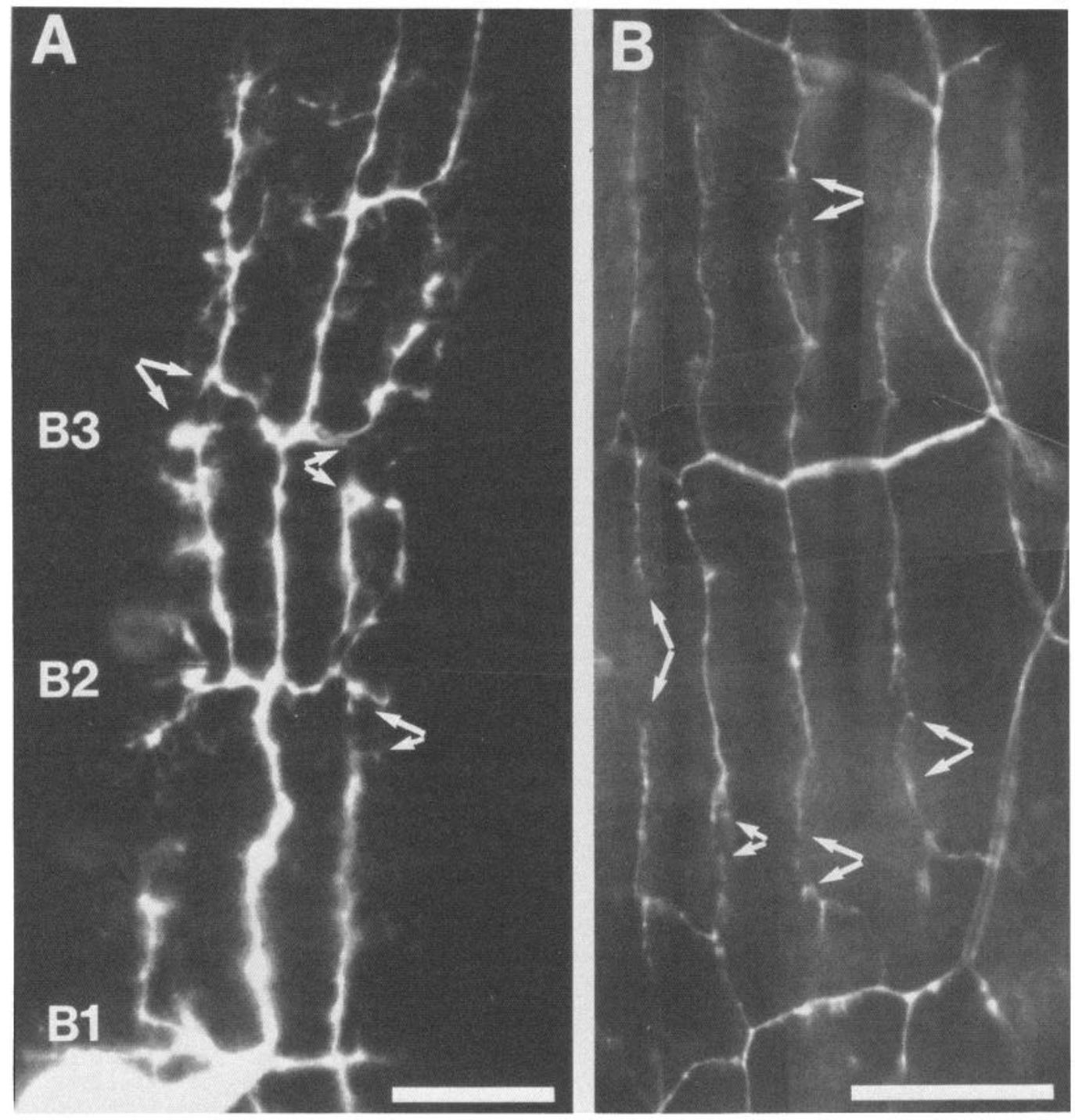

Figure 9. Growth-limiting self-encounters of $\mathrm{P}_{\mathrm{v}}$ neuron axons, as seen among peripheral axons of Lucifer Yellow-filled $\mathrm{P}_{\mathrm{v}}$ neurons photographed in whole mount. $A$, The major field axons at stage $10(2 / 5)$. Laterally directed second-order annular branches from B1 and B2 branches encounter the B2 and B3 branches, respectively (at arrows). These axons are spatially separated, but focusing through the preparation revealed apparent filopodial contacts between the encountering branches; filopodia projecting from ends of axons are blurred in the photograph. $B$, Encounter of fourth-order circular branches in a neuron in the midbody at stage 11(2/20). Circular branches growing from neighboring third-order longitudinal branches along the same circumferential path encounter each other at arrows (that point to ends of axons) and are separated. Blurred filopodia are visible between the ends of some pairs of circular branches. The thick, faintly fluorescent circumferential stripe beneath each row of circular branches is an autofluorescent circular muscle fiber. Calibration, $50 \mu \mathrm{m}$.

positions, and from these, finally, fourth-order circular branches grow out along specific circumferential pathways and arborize in the epidermis to form sensory endings. Except for a few short first-order longitudinal branches which may grow from the central branch before the basic branching pattern is completed, virtually all of the axon branches that are extended appear to form part of the late embryonic (essentially mature) field structure.

This stereotyped pattern of development is so robust that in segments where the B1p branch is missing and is replaced by a secondary axon that has emerged directly from the CNS (Fig. 10A), that secondary axon develops the branching pattern typical for a B1p branch. One interpretation of this stereotyped pattern of receptive field development is that the peripheral axons of the $\mathrm{P}_{\mathrm{V}}$ neuron grow along prespecified pathways. Musclé fibers might be important components of such pathways, since the embryonic branching pattern of the peripheral axons of the $\mathrm{P}_{\mathrm{V}}$ neuron bears a close relation to the orthogonal grid of primordial longitudinal and circular muscle fibers in the germinal plate (Fig. 4; Kramer and Stuart, 1982). This interpretation is supported by the observation that the primary axon of the $\mathrm{P}_{\mathrm{D}}$ neuron apparently grows along a pathway of particular muscle and other mesodermal cells (Kuwada, 1982; Kuwada and Kramer, 1983).

Determinants of subfield structure. In the development of some nervous systems, an orderly temporal sequence of outgrowth of axons from the neurons has been shown to be responsible for the formation of appropriate neuronal connections (e.g., Anderson, 1978; Macagno, 1978). 


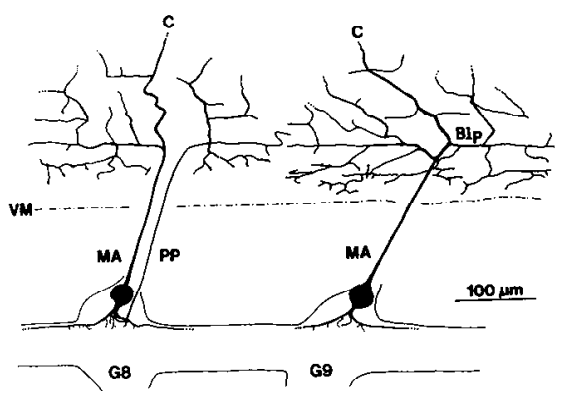

A

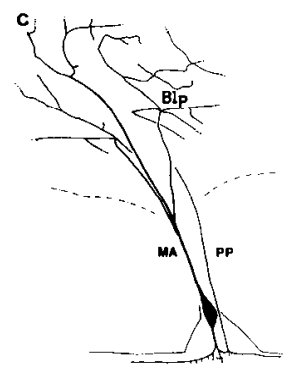

B

Figure 10. Variations in the development of secondary axon subfields of $\mathrm{P}_{\mathrm{V}}$ neurons; tracings from photographs of neurons filled with Lucifer Yellow. $A$, Two $\mathrm{P}_{\mathrm{v}}$ neurons in adjacent ganglia of a stage $11(0 / 20)$ embryo. The $P_{V}$ neuron in the 8 th abdominal ganglion $(G 8)$ has a secondary $(P P)$ axon with a large arborization in the posterior segmental germinal plate. The primary and secondary axon arborizations are completely non-overlapping. The primary $(M A)$ axon lacks a Blp branch. The $\mathrm{P}_{\mathrm{V}}$ neuron in $G 9$ lacks a secondary axon, and its primary axon $(M A)$ has a $\mathrm{B} 1 \mathrm{p}$ branch that occupies a territory homologous to that occupied by the secondary axon from $\mathrm{P}_{\mathrm{V}}$ in $G 8$. $B, \mathrm{P}_{\mathrm{v}}$ neuron in a different, stage $10(4 / 5)$ embryo. This neuron has a secondary axon, but that axon has not formed an appreciable arborization in the germinal plate. However, the primary axon of this neuron has a B1p branch with its normal arborization.

In the case of the primary axons of the $P_{V}$ and $P_{D}$ neurons, temporal differences of outgrowth between them do not appear to determine which territory of segmental skin each will innervate, since both neurons initiate growth of their primary axon at about the same time (Kuwada and Kramer, 1983) and begin to innervate their respective peripheral territories at the same time (Fig. 2A). However, temporal differences of outgrowth between primary and secondary axons of the same neuron might very well determine the territory where each axon will form its subfield. For instance, the primary axon of the $P_{D}$ neuron, which is first to emerge, grows directly to the dorsal germinal plate, and the secondary axons, which emerge later, grow directly into the ventral germinal plate. Thus, the first axons of the $P_{D}$ neuron bypass the ventral germinal plate, even though they initially contact it, whereas later axons innervate the ventral plate. Timing of outgrowth could play a role in this differential innervation pattern if, for instance, the $P_{D}$ neuron switches its preference from dorsal to ventral territories between the time of primary and secondary axon outgrowth, or if the attractiveness of the ventral territory for the $\mathrm{P}_{\mathrm{D}}$ neuron increases between the two periods of axon outgrowth.

The timing of axon outgrowth is likely to determine also the size and shape of neuronal subfields. Thus, in the case of the $P_{V}$ neuron, the primary axon grows out before either the minor field axons or the sccondary axon, and the primary subfield it forms is larger than either the minor subfields or the secondary subfield. Furthermore, it appears that the secondary axon sometimes grows out before the B1p branch is extended, in which case the secondary subfield replaces the subfield of the B1p branch, and when the reverse is the case, the

B1p branch subfield is larger than the secondary subfield, if it is present. Similarly, we propose that the first annular branch extended from a B2 branch sometimes precedes the B3 branch into territory normally occupied by a B3 branch, with the result that the subfield of the B3 branch either is missing or shifted to another territory. Thus subfield axons appear to occupy peripheral territory on a first-come-first-served basis. That is to say, each new branch of an axon of the $P_{\mathrm{v}}$ neuron grows only into a place in the periphery that is not occupied by another branch of the same neuron. This mutual territorial exclusion of axon branches of the same neuron (which we designate as isoneuronal branches) can be regarded as the consequence of a developmental rule, which can be inferred from our observations: isoneuronal branches do not grow across each other on the same substrate (Figs. 7, $B$ to $E$, and 9). By contrast, branches belonging to different, though serially or contralaterally homologous neurons (which we designate as heteroneuronal branches) are not subject to that restriction (Fig. $7 A$ ). The sharp boundaries between the subfields of a mechanosensory neuron are attributable to this rule. As seen in Figure 8, the developing major field of the $\mathrm{P}_{\mathrm{V}}$ neuron continues to expand longitudinally, even as it interpenetrates the major field of the serially homologous $P_{V}$ neuron in an adjacent segment. However, expansion stops as the major field branches encounter their isoneuronal minor field branches growing in the adjacent segment.

The source of the mutual territorial exclusion by isoneuronal branches could, in principle, be a competition among isoneuronal branches for a limited number of peripheral targets. In this case, each individual neuron would have to have its own set of targets that are labeled to designate them for just that one neuron so that homologous heteroneuronal branches that share the same territory would not compete. This seems an unlikely possibility because isoneuronal mutual exclusion is already manifest at the earliest stages of axon outgrowth, when the axons are growing in the muscle layer, long before they reach their epidermal targets. Thus a more attractive explanation is that isoneuronal, but not homologous heteroneuronal, axons avoid each other when growing on the same substrate (Kramer, 1982). This selfavoidance would require that processes projected by a neuron be able to distinguish between self and non-self. This self-recognition of two growing axonal processes might be mediated by their numerous filopodia, which may reach lengths up to $50 \mu \mathrm{m}$ and do appear to make mutual contacts. In line with this possibility, it has been proposed that filopodia play an important role in the recognition and choice of axonal growth pathways by insect neurons (Goodman et al., 1982; Ho and Goodman, 1982; Taghert et al., 1982; Keshishian and Bentley, 1983; Raper et al., 1983a, b).

Non-overlap of isoneuronal processes could be a general phenomenon of neuronal development, since the adult morphology of many neurons appears to satisfy the rule that isoneuronal processes do not cross each other on the same substrate. This property is especially apparent in the leech mechanosensory neurons, because each neuron has several distinct axons that innervate neigh- 
boring regions in the same spatial plane. Other neurons with two-dimensional fields of processes for which this property is similarly evident are alpha cells of retina and cerebellar Purkinje cells. The functional role for such a "self-avoidance" phenomenon could be, for instance, to ensure an optimal coverage of the available target territory.

\section{References}

Anderson, H. (1978) Postembryonic development of the visual system of the locust, Schistocerca gregaria. J. Embryol. Exp. Morphol. 45: 55-83.

Blackshaw, S. E. (1981a) Morphology of nociceptive terminals in the body wall of the leech. J. Physiol. (Lond.) 317: 8182P.

Blackshaw, S. E. (1981b) Morphology and distribution of touch cell terminals in the skin of the leech. J. Physiol. (Lond.) 320: 219-228.

Brown, M. C., J. K. S. Jansen, and D. Van Essen (1976) Polyneuronal innervation of skeletal muscle in new-born rats and its elimination during maturation. J. Physiol. (Iond.) 261: 387-422.

Goodman, C. S., J. A. Raper, R. Ho, and S. Chang (1982) Pathfinding by neuronal growth cones in grasshopper embryos. Symp. Soc. Dev. Biol. 40: 275-316.

Ho, R. K., and C. S. Goodman (1982) Peripheral pathways are pioneered by an array of central and peripheral neurones in grasshopper embryos. Nature 297: 404-406.

Hubel, D. H., T. N. Wiesel, and S. LeVay (1977) Plasticity of ocular dominance columns in monkey striate cortex. Philos. Trans. R. Soc. Lond. Biol. 278: 377-409.

Keshishian, H., and D. Bentley (1983) Embryogenesis of peripheral nerve pathways in grasshopper legs. I. The initial nerve pathway to the CNS. Dev. Biol. 96: 89-102.

Kramer, A. P. (1982) The development of neuronal arborizations in the leech. In Neuronal Development: Cellular Approaches in Invertebrates, C. Goodman and K. Pearson, eds., NRP Bulletin, pp. 882-885, MIT Press, Cambridge, MA.

Kramer, A. P., and J. R. Goldman (1981) The nervous system of the glossiphoniid leech Haementeria ghilianii. I. Identification of neurons. J. Comp. Physiol. 144: 435-448.

Kramer, A. P., and D. K. Stuart (1982) Muscle cells, glial cells and axonal guidance in leech embryos. Soc. Neurosci. Abstr. 8: 16.

Kretz, J. R., G. S. Stent, and W. B. Kristan, Jr. (1976) Photosensory input pathways in the medicinal leech. J. Comp. Physiol. 106: 1-37.

Kuffler, D. P., and K. J. Muller (1974) The properties and connections of supernumerary sensory and motor nerve cells in the central nervous system of an abnormal leech. $\mathrm{J}$. Neurobiol. 5: 331-348.

Kuwada, J. Y. (1982) Primary axon outgrowth in embryonic leech neurons. In Neuronal Development: Cellular Approaches in Invertebrates, C. Goodman and K. Pearson, eds., NRP Bulletin, pp. 879-882, MIT Press, Cambridge, MA.

Kuwada, J. Y., and A. P. Kramer (1983) Embryonic development of the leech nervous system: Primary axon outgrowth of identified neurons. J. Neurosci. 3: 2098-2111.

Lichtman, J. W. (1977) The reorganization of synaptic connexions in the rat submandibular ganglion during post-natal development. J. Physiol. (Lond.) 273: 155-177.

Lichtman, J. W., and D. Purves (1980) The elimination of redundant preganglionic innervation to hamster sympathetic ganglion cells in early post-natal life. J. Physiol. (Lond.) 301: 213-228.

Macagno, E. R. (1978) A mechanism for the formation of synaptic connections in the arthropod visual system. Nature 275: $318-320$.

Mann, K. H. (1962) Leeches (Hirudinea), Pergamon Press, Oxford

Muller, K. J., J. G. Nicholls, and G. S. Stent (1981) Neurobiology of the Leech, Cold Spring Harbor Laboratory, Cold Spring Harbor, NY.

Nicholls, J. G., and D. A. Baylor (1968) Specific modalities and receptive fields of sensory neurons in CNS of the leech. $\mathrm{J}$. Neurophysiol. 31: 740-756.

Jrt, C. A., W. B. Kristan, Jr., and G. S. Stent (1974) Neuronal control of swimming in the medicinal leech. II. Identification and connections of motor neurons. J. Comp. Physiol. 94: 121-154.

Rakic, P. (1976) Prenatal genesis of connections subserving ocular dominance in the rhesus monkey. Nature 261: 467471.

Raper, J. A., M. Bastiani, and C. S. Goodman (1983a) Pathfinding by neuronal growth cones in grasshopper embryos. I. Divergent choices made by the growth cones of sibling neurons. J. Neurosci. 3: 20-30.

Raper, J. A., M. Bastiani, and C. S. Goodman (1983b) Pathfinding by neuronal growth cones in grasshopper embryos. II. Selective fasciculation onto specific axonal pathways. J. Neurosci. 3: 31-41.

Taghert, P. H., M. J. Bastiani, R. K. Ho, and C. S. Goodman (1982) Guidance of pioneer growth cones: Filopodial contacts and coupling revealed with an antibody to Lucifer yellow. Dev. Biol. 94: 391-399.

Yau, K-W. (1976) Receptive fields, geometry and conduction block of sensory neurones in the central nervous system of the leech. J. Physiol. (Lond.) 263: 513 .538. 